\title{
Blood Glucose Control Among Critically Ill Patients with Brain Injury
}

\author{
Michael J. Jacka, Clinton J. Torok-Both, Sean M. Bagshaw
}

\begin{abstract}
Objective: To evaluate the incidence of hypoglycemia, hyperglycemia and blood glucose (BG) variability in brain-injured patients and their association with clinical outcomes. Methods: Retrospective cohort study of brain-injured patients admitted to an 11bed neurosciences intensive care unit (ICU) from January 1 to December 31, 2003. Results: We included 606 patients. Mean age was 52.3 years, $60.6 \%$ were male, $11.9 \%$ had diabetes mellitus, and $64 \%$ were post-operative. Seventy-five $(12.4 \%)$ received intensive insulin therapy (IIT) for a median (IQR) 72 (24-154) hours. Hypoglycemia and hyperglycemia occurred in $4.6 \%$ (96.4\% receiving IIT) and $9.6 \%$ (77.6\% receiving IIT). Median number of episodes per patient was $3(75 \%$ with $\geq 2)$ and 4 ( $81 \%$ with $\geq 2)$ for hypoglycemia and hyperglycemia. Variable glycemic control occurred in $3.8 \%$ (100\% receiving IIT) with median number of 13 episodes per patient. In-hospital mortality was $16.7 \%$, median (IQR) ICU and hospital lengths of stay were 2 (1-5) and 8 (3-19) days. Hypoglycemia, hyperglycemia and BG variability showed non-significant but consistent associations with hospital mortality and prolonged lengths of ICU and hospital stay. The rate of recurrence of episodes showed stronger and significant associations with outcome, in particular for BG variability and hyperglycemia. Conclusions: Hypoglycemia, hyperglycemia and BG variability are relatively common in braininjured patients and are associated with IIT. An increased frequency of episodes, in particular for BG variability and hyperglycemia, was associated with greater risk of both hospital death and prolonged duration of stay.
\end{abstract}

RÉSUMÉ: Maîtrise de la glycémie chez les patients atteints d'un traumatisme cérébral dont l'état est critique. Objectif : Le but de l'étude était d'évaluer l'incidence de l'hypoglycémie, de l'hyperglycémie et de la variabilité du glucose sanguin (GS) chez les patients atteints d'un traumatisme cérébral ainsi que la relation à l'issue clinique. Méthodes : Il s'agit d'une étude rétrospective sur une cohorte de patients atteints d'un traumatisme cérébral admis à une unité de soins intensifs neurologiques (USI) de 11 lits entre le 1er janvier et le 31 décembre 2003. Résultats : Six cent six patients, dont l'âge moyen était de 52,3 ans, ont été inclus dans l'étude. De plus, 60,6\% étaient des hommes, 11,9\% étaient diabétiques et 64\% avaient subi une chirurgie. Soixante-quinze patients $(12,4 \%)$ ont reçu une insulinothérapie intensive (ITI) dont la durée médiane était de 72 heures (écart interquartile de 24 à 154 heures). De l'hypoglycémie a été observée chez 4,6\% (96,4\% recevaient une ITI) et de l'hyperglycémie chez 9,6\% (77,6\% recevaient une ITI). Le nombre médian d'épisodes d'hypoglycémie par patient était de 3 (75\% ont eu $\geq 2$ épisodes) et le nombre médian d'épisodes d'hyperglycémie par patient était de 4 ( $81 \%$ ont eu $\geq 2$ épisodes). Une maîtrise variable du GS a été observée chez 3,8\% (100\% sous ITI) et le nombre médian d'épisodes par patient était de 13. La mortalité hospitalière était de $16,7 \%$, la durée de séjour médiane à l'USI de 2 jours (écart interquartile de 1 à 5 jours) et la durée d'hospitalisation de 8 jours (écart interquartile de 3 à 19 jours). L'hypoglycémie, l'hyperglycémie et la variabilité du GS étaient associées de façon constante mais non significative à la mortalité hospitalière et à une durée prolongée du séjour à l'USI et du séjour à l'hôpital. L'association entre le taux de récidive des épisodes et l'issue était plus marquée et significative, particulièrement en ce qui concerne la variabilité du GS et l'hyperglycémie. Conclusions : L'hypoglycémie, l'hyperglycémie et la variabilité du GS sont relativement fréquentes chez les patients atteints d'un traumatisme cérébral et sont associées à l'ITI. Une fréquence accrue d'épisodes, en ce qui concerne surtout la variabilité du GS et l'hyperglycémie, était associée à un risque plus élevé de mortalité hospitalière et d'un séjour hospitalier prolongé.

Can. J. Neurol. Sci. 2009; 36: 436-442

Tight glycemic control (TGC) with intensive insulin therapy (IIT) has been shown in selected randomized trials to improve morbidity and mortality in critically ill patients. ${ }^{1-5}$ Data from these trials suggest blood glucose (BG) values should ideally be maintained in the range of 4.4-6.1 $\mathrm{mmol} / \mathrm{L}$ for TGC to exert its clinical benefit. ${ }^{1,4}$ Based on these findings, the use of IIT to achieve TGC and avoid hyperglycemia has been widely advocated and increasingly suggested as the standard of care..$^{6,7}$ However, recently, the findings of the multi-centre multinational NICE-SUGAR (Normglycemia in Intensive Care Evaluation -Survival Using Glucose Algorithm Regulation) randomized trial comparing IIT with less-intensive insulin therapy in 6104 critically ill patients has suggested the use of IIT is associated with a higher 90 -day mortality (27.5\% vs. $24.9 \%$; OR $1.14,95 \%$ CI 1.02-1.28, $\mathrm{p}=0.02) .^{8}$

These studies, however, were primarily focused on mixed medical-surgical, cardiac surgical or cardiac ICU

From the Department of Anaesthesiology and Pain Medicine (MJJ, CJTB), Division of Critical Care Medicine (MJJ, CJTB, SMB), Faculty of Medicine and Dentistry, University of Alberta, Edmonton, Alberta, Canada.

Received February 13, 2009. Final Revisions Submitted March 27, 2009. Correspondence to: Sean M Bagshaw, Division of Critical Care Medicine, Faculty of Medicine and Dentistry, University of Alberta, 3C1.12 Walter C. Mackenzie Centre, 8440-112 Street, Edmonton, Alberta, T6G 2B7, Canada. 
patients ${ }^{1,2,4,5,9,10}$ and relatively few specifically focused on critically ill patients with primary neurologic injury. ${ }^{11-16}$ The brain-injured may represent a distinct subgroup of critically ill patients with an unpredictable and variable cerebral response to systemic hypoglycemia or hyperglycemia and use of IIT. For example, in a retrospective study of 20 critically ill patients with severe traumatic brain injury (TBI) monitored with brain tissue microdialysis, Oddo et al found maintaining systemic TGC with IIT was associated with a greater prevalence of brain energy crisis that correlated with increased mortality. ${ }^{13}$ Importantly, the brain-injured patient may not manifest the typical symptoms of extremes in BG values due to their underlying condition and therefore, risk delayed detection. Likewise, variability in glycemic control has increasingly been recognized to have important association with worse clinical outcome. ${ }^{17-21}$ Variability in BG control could, in theory, exacerbate braininjury due to unpredictable intracranial osmotic shifts.

The issue of TGC with IIT in the critically ill, in particular those with brain injury, remains controversial. ${ }^{14,22}$ More recently, data have emerged to suggest TGC with IIT may, in selected circumstances, be associated with harm from increased risk of hypoglycemia ${ }^{11,23-25}$ and observational data have indicated that even a single episode of hypoglycemia is associated with higher risk of death. ${ }^{26}$

Accordingly, we performed a one-year surveillance of all critically ill brain-injured patients admitted to a dedicated neurologic ICU at a single tertiary academic institution to describe: 1) incidence of hypoglycemia; 2) incidence of hyperglycemia; 3) variability in BG control; 4) the association of use of IIT and BG control; and 4) the association of BG control with length of stay and hospital mortality.

Table 1: Baseline characteristics and outcome stratified by use of intensive insulin therapy in NICU patients.

\begin{tabular}{|c|c|c|c|c|}
\hline Characteristic & $\begin{array}{l}\text { Cohort } \\
(n=606)\end{array}$ & $\begin{array}{l}\text { No-ITT } \\
(n=531)\end{array}$ & $\underset{(n=75)}{\text { IIT }}$ & $\begin{array}{c}\text { p- } \\
\text { value }\end{array}$ \\
\hline Age (mean [SD]) (years) & $52.3(17)$ & $51.6(17)$ & $57.3(17)$ & 0.006 \\
\hline Male Sex (\%) & $367(60.6)$ & $317(59.7)$ & $50(66.7)$ & 0.26 \\
\hline $\begin{array}{c}\text { Admission Category (\%) } \\
\text { Surgical } \\
\text { Medical } \\
\text { Trauma } \\
\end{array}$ & $\begin{array}{c}388(64.0) \\
125(20.6) \\
93(15.3) \\
\end{array}$ & $\begin{array}{c}348(65.5) \\
110(20.7) \\
73(13.8) \\
\end{array}$ & $\begin{array}{l}40(53.3) \\
15(20.0) \\
20(26.7) \\
\end{array}$ & 0.02 \\
\hline $\begin{array}{c}\text { Diabetes Mellitus (\%) } \\
\text { None } \\
\text { Type I } \\
\text { Type II } \\
\end{array}$ & $\begin{array}{c}534(88.1) \\
19(3.1) \\
53(8.7)\end{array}$ & $\begin{array}{c}514(96.8) \\
5(0.9) \\
12(2.3)\end{array}$ & $\begin{array}{l}20(26.7) \\
14(18.7) \\
41(54.7)\end{array}$ & $\begin{array}{l}<0.001 \\
<0.001 \\
<0.001\end{array}$ \\
\hline $\begin{array}{l}\text { Hypoglycemia }(\mathrm{n}, \%) \\
\text { Hyperglycemia }(\mathrm{n}, \%)\end{array}$ & $\begin{array}{l}28(4.6) \\
58(9.6)\end{array}$ & $\frac{1(0.2)}{30(40.0)}$ & $\frac{27(36.0)}{45(60.0)}$ & $\begin{array}{l}<0.001 \\
<0.001\end{array}$ \\
\hline BG Variabili & & & $23(30.7)$ & $<0.001$ \\
\hline $\begin{array}{l}\text { ICU stay (median [IQR]) } \\
\text { (days) }\end{array}$ & $2(1-5)$ & $2(1-4)$ & $4(1-12)$ & $<0.001$ \\
\hline $\begin{array}{c}\text { Hospital stay (median } \\
{[\mathrm{IQR}] \text { ) (days) }}\end{array}$ & $8(3-19)$ & $7(3-18)$ & $13(8-34)$ & $<0.001$ \\
\hline Hospital Death (\%) & $101(16.7)$ & $85(16)$ & $16(21.3)$ & 0.25 \\
\hline
\end{tabular}

IIT = intensive insulin therapy; $\mathrm{BG}=$ blood glucose; $\mathrm{ICU}=$ intensive care unit

\section{METHODS}

\section{Study Population and Setting}

This was a retrospective observational cohort study. We identified all adult critically ill patients with a primary neurologic diagnosis admitted to the Neurosciences Intensive Care Unit (NICU), a dedicated neurologic 11-bed mixed medical, surgical and trauma ICU, at the University of Alberta Hospital between January 1, 2003 and December 31, 2003. The Health Research Ethics Board at the University of Alberta approved this study.

\section{Study Protocol}

Selected clinical (i.e. age, sex, admission type, diabetes mellitus $[\mathrm{DM}]$ ), laboratory (i.e. BG) and outcome data (i.e. ICU, hospital survival, ICU length of stay) data were extracted. All patients receiving intravenous intensive insulin therapy for blood glucose control were identified by review of medical records. Data were also extracted on episodes of hypoglycemia, hyperglycemia and BG variability.

\section{Operational Definitions}

Hypoglycemia was defined as a $\mathrm{BG}<4.0 \mathrm{mmol} / \mathrm{L}$ and hyperglycemia as a $\mathrm{BG} \geq 10.0 \mathrm{mmol} / \mathrm{L}$. These values were chosen to represent BG values below the lower threshold of TGC ( $4.4 \mathrm{mmol} / \mathrm{L})$ and likewise above the threshold for initiation of IIT $(10.0 \mathrm{mmol} / \mathrm{L})$ in the standard or control arms from randomized trials. ${ }^{1,2,4,11,12}$ We defined $B G$ variability as any patient who had both a hypoglycemic and a hyperglycemic measurement during their ICU admission. ${ }^{20}$ The enumerated blood glucose values did not include the index episode that led to initiation of the insulin in those receiving IIT.

Table 2: Summary of clinical characteristics and outcomes stratified by BG control

\begin{tabular}{|c|c|c|c|c|}
\hline Characteristic & $\begin{array}{l}\text { Neither } \\
(n=543)\end{array}$ & $\begin{array}{l}\text { Hypoglycemia } \\
\quad(n=28)\end{array}$ & $\begin{array}{l}\text { Hyperglycemia } \\
\qquad(\mathrm{n}=58)\end{array}$ & $\begin{array}{c}\text { BG } \\
\text { Variability } \\
(\mathbf{n}=\mathbf{2 3})\end{array}$ \\
\hline $\begin{array}{l}\text { Age (mean }[\mathrm{SD}]) \\
\text { (years) }\end{array}$ & $51.6(17.2)$ & $58.5(16.5)$ & $57.3(17)$ & $57.0(15.9)$ \\
\hline Male Sex (\%) & $329(60.6)$ & $16(57.1)$ & $50(66.7)$ & $15(65.2)$ \\
\hline $\begin{array}{l}\text { Admission } \\
\text { Category (\%) } \\
\text { Surgical } \\
\text { Medical } \\
\text { Trauma } \\
\end{array}$ & $\begin{array}{c}354(65.2) \\
112(20.6) \\
77(14.2)\end{array}$ & $\begin{array}{l}18(64.3) \\
5(17.9) \\
5(17.9)\end{array}$ & $\begin{array}{l}40(53.3) \\
15(20.0) \\
20(26.7)\end{array}$ & $\begin{array}{c}15(65.2) \\
4(17.4) \\
4(17.4) \\
\end{array}$ \\
\hline $\begin{array}{l}\text { Diabetes } \\
\text { Mellitus (\%) } \\
\text { None } \\
\text { Type I } \\
\text { Type II }\end{array}$ & $\begin{array}{c}511(94.1) \\
5(1.0) \\
27(5.0)\end{array}$ & $\begin{array}{c}10(35.7) \\
3(10.7) \\
15(53.6)\end{array}$ & $\begin{array}{l}20(26.7) \\
14(18.7) \\
41(54.7)\end{array}$ & $\begin{array}{c}9(39.1) \\
3(13.0) \\
11(47.8) \\
\end{array}$ \\
\hline $\begin{array}{l}\text { ICU stay (median } \\
{[\text { IQR]) (days) }}\end{array}$ & $2(1-4)$ & $7(4-18)$ & $4(1-12)$ & $11(4-19)$ \\
\hline $\begin{array}{l}\text { Hospital stay } \\
\text { (median } \\
{[\text { IQR]) (days) }}\end{array}$ & $8(3-18)$ & $24(10-39)$ & $13(8-34)$ & $27(9-40)$ \\
\hline Hospital Death (\%) & $87(16.0)$ & $7(25.0)$ & $16(21.3)$ & $6(26.1)$ \\
\hline
\end{tabular}

$\mathrm{BG}=$ blood glucose; $\mathrm{ICU}=$ intensive care $u$ it 
Table 3: Summary of patient characteristics, and BG control stratified by hospital mortality

\begin{tabular}{|c|c|c|c|}
\hline \multirow[t]{2}{*}{ Characteristic } & \multicolumn{2}{|c|}{$\begin{array}{c}\text { Hospital Discharge } \\
\text { Status }\end{array}$} & \multirow[t]{2}{*}{ p-value } \\
\hline & $\begin{array}{c}\text { Dead } \\
(\mathrm{n}=101)\end{array}$ & $\begin{array}{c}\text { Alive } \\
(\mathrm{n}=505)\end{array}$ & \\
\hline Age (mean [SD]) (years) & $52.0(17.3)$ & $52.4(17.0)$ & 0.87 \\
\hline Male Sex $(\%)$ & $53(52.5)$ & $314(62.2)$ & 0.08 \\
\hline $\begin{array}{c}\text { Admission Category }(\%) \\
\text { Surgical } \\
\text { Medical } \\
\text { Trauma } \\
\end{array}$ & $\begin{array}{l}43(88.9) \\
29(23.2) \\
29(31.2) \\
\end{array}$ & $\begin{array}{l}345(11.1) \\
96(76.8) \\
64(68.8) \\
\end{array}$ & $<0.001$ \\
\hline $\begin{array}{c}\text { Diabetes Mellitus (n, \%) } \\
\text { None } \\
\text { Type I } \\
\text { Type II } \\
\text { Any }\end{array}$ & $\begin{array}{l}86(16.1) \\
6(31.6) \\
9(17.0) \\
15(20.8)\end{array}$ & $\begin{array}{l}448(83.9) \\
13(68.4) \\
44(83.0) \\
57(79.2)\end{array}$ & 0.21 \\
\hline $\begin{array}{c}\text { IIT }(\mathrm{n}, \%)(\mathrm{n}=75) \\
\text { Duration IIT (median } \\
[\mathrm{IQR}]) \text { (hours) }\end{array}$ & $\begin{array}{c}16(21.3) \\
72(20- \\
120) \\
\end{array}$ & $\begin{array}{c}59(78.7) \\
72(24-168)\end{array}$ & $\begin{array}{l}0.25 \\
0.40\end{array}$ \\
\hline $\begin{array}{c}\text { Hypoglycemia } \\
\text { Incidence }(\mathrm{n}, \%) \\
\text { Episodes per patient } \\
(\text { median }[\mathrm{IQR}])^{\boldsymbol{\pi}}\end{array}$ & $\begin{array}{l}21(4.2) \\
3(1-6)\end{array}$ & $\begin{array}{l}7(6.9) \\
2(2-5)\end{array}$ & $\begin{array}{l}0.29 \\
0.87\end{array}$ \\
\hline $\begin{array}{c}\text { Hyperglycemia } \\
\text { Incidence (n, \%) } \\
\text { Episodes per patient } \\
\text { (median [IQR]) }\end{array}$ & $\begin{array}{c}13(12.9) \\
5(2-28)\end{array}$ & $\begin{array}{c}45(8.9) \\
3(2-9)\end{array}$ & $\begin{array}{l}0.26 \\
0.11\end{array}$ \\
\hline $\begin{array}{c}\text { BG Variability } \\
\text { Incidence (n, \%) } \\
\text { Episodes per patient } \\
\text { (median [range]) }\end{array}$ & $\begin{array}{c}6(26.1) \\
27(14-54)\end{array}$ & $\begin{array}{l}17(73.9) \\
10(5-16)\end{array}$ & $\begin{array}{l}0.62 \\
0.09\end{array}$ \\
\hline
\end{tabular}

IIT = intensive insulin therapy; BG = blood glucose; I Median (IQR) number of episodes per patient for those with at least one episode. clinical factors and crude outcomes, stratified by therapy with IIT, with hypoglycemia, hyperglycemia or BG variability. Continuous data were compared using Student's t-test, Mann Whitney U or Kruskal-Wallis test as indicated. Differences in proportions among categorical data were assessed using Fisher's exact test or the chi ${ }^{2}$-test as appropriate. The association of events with lengths of stay and hospital mortality were evaluated in crude and multivariate logistic regression. Data are presented as crude and adjusted odds ratios (OR) with $95 \% \mathrm{CI}$. All analyses were performed using Stata Release 10 (Stata Corp, TX). Twosided $\mathrm{p}<0.05$, unadjusted for multiple testing, were considered to indicate statistical significance for all comparisons.

\section{RESULTS \\ Study Cohort}

We identified 606 critically ill patients with a primary neurologic diagnosis who were admitted to the NICU during the study period. The cohort had a mean (SD) age of 52.3 (17) years, $60.6 \%$ were male, $11.9 \%$ had DM, and most (64\%) were admitted for post-operative support.

We identified 75 patients (12.4\%) who received IIT (Table 1). These patients received IIT for a median (IQR; range) 72 (24154; 1-640) hours. Patients receiving IIT were older and more likely admitted with a primary trauma diagnosis (Table 1). Those with DM were significantly more likely to receive IIT compared with non-DM patients ( $73 \%$ vs. $3.2 \%$, Relative Risk [RR] 22.9, 95\% CI, 14.1-37.3).

\section{Blood Glucose Control}

A total of $10.4 \%(n=63)$ of patients experienced an episode of either hypoglycemia or hyperglycemia (Table 1). Of 28 patients (4.6\%) with an episode of hypoglycemia, $96.4 \%$ occurred in those receiving IIT (Table 2). Overall, 36\% of all patients receiving IIT had a hypoglycemic episode. These patients received IIT for a median (IQR) 149 (72-253) hours. The median

Table 4: Crude and adjusted logistic regression of hospital mortality in association with BG control

\begin{tabular}{c|c|c}
\hline Characteristic & $\begin{array}{c}\text { Crude OR } \\
\mathbf{( 9 5 \% ~ C I )}\end{array}$ & $\begin{array}{c}\text { Adjusted OR } \\
\mathbf{( 9 5 \% ~ C I ) ~}\end{array}$ \\
\hline $\begin{array}{c}\text { Hypoglycemia } \\
\text { Any }\end{array}$ & $1.72(0.71-4.15)$ & $2.04(0.62-6.70)$ \\
Number of Episodes (per episode) & $1.05(0.90-1.23)$ & $1.05(0.87-1.26)$ \\
\hline $\begin{array}{c}\text { Hyperglycemia } \\
\text { Any }\end{array}$ & $1.51(0.78-2.92)$ & $1.05(0.41-2.72)$ \\
Number of Episodes (per episode) & $1.05(1.01-1.09)$ & $1.04(1.00-1.09)$ \\
\hline $\begin{array}{c}\text { BG Variability } \\
\text { Any }\end{array}$ & $1.81(0.70-4.72)$ & $2.18(0.63-7.54)$ \\
Number of Episodes (per episode) & $1.04(1.01-1.08)$ & $1.04(1.00-1.08)$ \\
\hline
\end{tabular}

IIT = intensive insulin therapy; OR = odds ratio; I Adjustment for age, sex, diagnostic category, diabetes mellitus, intensive insulin therapy. 
(range) number of hypoglycemic episodes per patient was 3 (114) with $75 \%$ having $\geq 2$ episodes. Patients who had a hypoglycemic episode were older (58.5 vs. 52.0 years, $\mathrm{p}=0.05)$, were receiving IIT ( $36 \%$ vs. $0.2 \%$; RR 191.2, 95\% CI, 26.4$1386)$ and were more likely diabetic (25\% vs $1.9 \%$, RR 13.4 , 95\% CI, 6.4-27.8).

Of 58 patients $(9.6 \%)$ having an episode of hyperglycemia, $77.6 \%$ were receiving IIT (Table 2). The median (IQR) duration of IIT in these patients was 72 (12-144) hours. The median (range) number of hyperglycemic episodes was 4 (1-63) with $81 \%$ have $\geq 2$ episodes. Patients having hyperglycemia episodes were older (57.8 vs. 51.7 years, $\mathrm{p}=0.01)$, were receiving IIT (60\% vs. $2.4 \%$; RR $24.5,95 \%$ CI, 13.9-43.2) were more likely diabetic (50\% vs $4.1 \%$, RR $12.1,95 \%$ CI, 7.6-19.4) and more likely surgical admissions (46.6\% vs. $34.9 \%$, RR 1.33, 95\% CI, 0.99-1.80). Marked hyperglycemia (BG $>16.0 \mathrm{mmol} / \mathrm{L}$ ) occurred in $5.0 \%$ of the cohort. These patients had a median (range) 3.5 (1-49) episodes per patient.

Variability in BG control occurred in 23 patients (3.8\%), 14 of whom had DM (60.9\%), and all (100\%) were receiving IIT. (Table 2) These patients had received IIT for a median (IQR) duration of 154 (72-240) hours and had a median (range) of 13 (2-69) episodes of either hypoglycemia or hyperglycemia per patient.

\section{Clinical Outcomes}

Overall crude in-hospital death was $16.7 \%$. The cohort had a median (IQR) duration of ICU and hospital stay of 2 (1-5) and 8 (3-19) days, respectively (Tables 1 and 3).

Hypoglycemia was associated with a non-significant increase in the odds of crude and adjusted hospital death (Table 4). Hypoglycemia was also associated with both longer median ([IQR]) durations of ICU (7 (3.5-7) days vs. 2 (1-4) days, $\mathrm{p}<0.001)$ and hospital (24 days (9.5-39) vs. 8 (3-18) days) stay, respectively.

Any episode of hyperglycemia was associated with a nonsignificant increase in crude and adjusted odds of hospital death (Table 4). Patients with more frequent episodes had a trend towards higher hospital death (Table 3). Moreover, an increase in episodes of hyperglycemia was associated with significantly higher crude and adjusted odds of hospital death (Table 4). Hyperglycemia was also associated with higher median (IQR) ICU (4 (1-12) days vs. 2 (1-4) days, p=0.0008) and hospital (13 (732) days vs. 8 (3-18) days, $\mathrm{p}=0.003)$ duration of stay.

Variability in BG control was associated with higher crude mortality compared with those having hypoglycemia or hyperglycemia alone (Table 2). Any BG variability was associated with a non-significant increase in crude and adjusted odds of hospital death (Table 4). Similarly, an increase in number of episodes (cumulative hypoglycemia and hyperglycemia episodes) showed trends towards higher hospital death (Table 3). In crude and adjusted analysis, the number of episodes contributing to BG variability was significantly associated with hospital death (Table 4). Variability in BG control was associated with the longest durations of stay in both ICU and hospital (Table 1).

\section{DISCUSSION}

We conducted a one-year surveillance of glycemic control in critically ill brain-injured patients admitted to a dedicated neurosciences ICU to evaluate the incidence of hypoglycemia, hyperglycemia and BG variability and describe their association with use of IIT, duration of stay in ICU and hospital survival.

We identified $10.4 \%$ of patients as having either hypoglycemia or hyperglycemia during admission to NICU. We found hypoglycemic episodes occurred in $4.6 \%$ of patients, and nearly all were receiving IIT. Moreover, hypoglycemia recurred frequently, with $75 \%$ of patients having $\geq 2$ discrete episodes. We also showed hyperglycemic episodes were relatively common, occurring in $9.6 \%$ of patients, the vast majority of whom were receiving IIT, and $81 \%$ had recurrent episodes (this excluded initial episode prompting IIT initiation). In $3.8 \%$ of patients, all of whom were receiving IIT, there was variability in glycemic control with frequently repeated episodes of both hypoglycemia and hyperglycemia. ${ }^{17}$ Diabetic patients were not only more likely to receive IIT, but also likely to have greater BG variability. ${ }^{17}$ In our study, we found no statistically significant association between in-hospital mortality and the occurrence of an episode of hypoglycemia, hyperglycemia or BG variability. However, our data did show consistent trends for higher crude and adjusted hospital mortality. Moreover, our study found increasing number of episodes of hyperglycemia and poor BG control (occurrence of both hypoglycemia and hyperglycemia) were associated with higher odds of hospital death. The occurrence of hypoglycemia, hyperglycemia and variability in BG control were associated with longer durations of ICU and hospital stay.

The use of IIT to achieve TGC among the critically ill has been suggested to reduce morbidity and mortality.,3-5 This premise, although adopted by recognized critical care societies ${ }^{6}$, is largely supported from studies of patients with primary myocardial pathology or mixed medical-surgical disease..$^{1,4,5}$ However, emerging data have questioned the efficacy of IIT and TGC, in particular, the optimal glycemic range to improve clinical outcomes while minimizing risk of adverse effects..$^{2,8,10,23-25}$ Several recent trials have suggested the apparent benefit of narrowly-regulated glycemic control and IIT may come at the expense of increased rates of hypoglycemia. . $^{2,8,10,23-25}$ The high incidence of hypoglycemia $(8.6-12.1 \%$ for $\mathrm{BG}<2.2$ $\mathrm{mmol} / \mathrm{L}$ ) in patients allocated to IIT has recently justified the premature termination of two large multi-centre randomized trials of TGC in the critically ill. ${ }^{24,27}$ The NICE-SUGAR trial described an incidence of severe hypoglycemia (BG $<2.2$ $\mathrm{mmol} / \mathrm{L}$ ) in $6.8 \%$ of those allocated to IIT (compared with only $0.5 \%$ in controls). ${ }^{8}$ Overall, these data suggest hypoglycemia may be far more common than appreciated..$^{22,26-28}$ While selected studies have indicated no association between hypoglycemia and mortality, ${ }^{29}$ Brunkhorst et al showed severe hypoglycemia was independently associated with a higher risk of death (hazard ratio $\left.^{30} 3.31,95 \% \mathrm{CI}, 2.23-4.90\right)$ along with greater duration of hospitalization. ${ }^{24}$ Importantly, despite data to suggest the duration of hypoglycemic episodes may be short (largely due to intensive monitoring), ${ }^{5,17}$ their recognition may be delayed, in particular in critically ill brain-injured patients. While $6.4 \%$ $(n=391)$ of patients enrolled in NICE-SUGAR had ICU admission associated with TBI, no specific data was presented on hypoglycemia, BG variability or outcomes for this subgroup. ${ }^{8}$ 
Two small randomized trials (total $n=175$ ) in acute subarachnoid hemorrhage and severe TBI failed to show IIT improved survival or neurologic outcome, however, it was associated with a higher rates of hypoglycemia. ${ }^{11,12}$ We contend that these brain-injured patients may represent an important and distinct subgroup of critically ill patients where systemic BG values do not necessary correlate with brain tissue glucose concentration. ${ }^{14}$ For example, in brain-injured patients whose cerebral metabolism is impaired, therapy with IIT to achieve TGC (BG 4.4-6.1 mmol/L) has been associated with significantly lower brain tissue glucose concentration and the precipitation of brain energy crises..$^{13,15,16}$ In a small study of TBI patients monitored with cerebral microdialysis, Oddo et al showed that TGC with IIT was associated with a higher prevalence of a cerebral glucose concentration $<0.7 \mathrm{mmol} / \mathrm{L}$ and a lactate/pyruvate ratio $>40$. This association with cerebral markers of brain energy crisis was further modified by lower systemic BG values and higher insulin dose. Moreover, these brain energy crises were associated with significantly higher adjusted odds of hospital death (OR 7.4, 95\% CI, 1.4-39.5). ${ }^{13}$ Recent data from two small microdialysis studies found similar findings with the use of IIT in patients with aneurismal subarachnoid hemorrhage. ${ }^{15,16}$ Both hypoglycemia and the therapeutic response can be neurologically detrimental, by precipitation of overt and subclinical status epilepticus, or exacerbation of cerebral edema and intracranial pressure that may lead to transtentorial herniation in extreme cases..$^{31-33}$ The frequency of hypoglycemia and BG variability in our study, where a range of 4-10 $\mathrm{mmol} / \mathrm{L}$ was generally targeted, raises concern regarding the use of IIT to achieve TGC in this population. Moreover, had a protocol to achieve "tighter" glycemic control been used similar to prior trials ${ }^{1,4,11,12,24,34}$, the incidence of hypoglycemia would likely have been higher.

While avoidance of overt (and sustained) hyperglycemia may have recognized importance for improving clinical outcomes in both general and brain-injured critically ill patients ${ }^{1,4,34}$, wide variability in glycemic control is increasingly recognized as an important aspect of BG control and has been associated with significant higher mortality in several observational studies. ${ }^{17}$ 21,35 In a retrospective analysis of 168337 BG measurements performed in cohort of 7049 critically ill patients, Egi et al found variability in BG values were independently associated with increased ICU and hospital death and prolonged duration of ICU stay. ${ }^{17}$ Moreover, this study found BG variability was a more powerful predictor of outcome than average BG values. Similarly, in a prospective observational study of 191 critically ill patients with sepsis receiving IIT, high BG variability (measured by SD of mean BG values) was associated with higher odds of death in multivariable analysis. ${ }^{35}$ In a retrospective analysis of a large cohort of consecutively admitted critically ill patients, Krinsley found the association between BG variability and mortality was strongest for BG in the normal range. In these patients, mortality for those with high BG variability (fourth quartile) was 5-fold greater when compared to those with low BG variability (first quartile).

Few investigations to date have specifically evaluated the impact of BG variability in brain-injured patients and clinical outcomes. ${ }^{36}$ In our study, $10.4 \%$ of all NICU patients had repeated BG values "out-of-range", and 3.8\% fulfilled criteria for BG variability. Moreover, 100\% of these patients with BG variability were receiving IIT. Whether this BG variability was attributable to the local IIT practice or related to the timely identification of abnormal BG values in brain-injured patients remains unclear. Importantly, however, our data showed this BG variability was associated with longer durations of both ICU and hospital stay and (non-significant) higher hospital death. Likewise, a higher rate of recurrence was associated with significantly higher crude and adjusted odds of hospital death. While these data do not establish causality, given the inherent limitations in our study, we believe these observations are important, largely consistent with the reported literature and should raise caution to the potential harm of IIT in brain-injured patients. The routine use of a standardized protocol of IIT to achieve TCG would be expected to reduce BG variability, however, in non-randomized trial settings (i.e. "real-world") this may be challenging to realize..$^{36,37}$ For example, in a small retrospective "before-and-after" study evaluating the implementation of an IIT protocol (target 4.4-6.1 mmol/L) in a neurosurgical ICU, Wittenberg et al found average BG values were lower after introduction of the protocol, however, this came at the expense of increased BG variability and a higher incidence of hypoglycemia. ${ }^{36}$ These findings have practical implications for the safe and effective use of "labour-intensive" IIT to achieve glycemic control in this population and draws attention to the possible need for protocols that are individualized. ${ }^{38}$

In addition to concerns regarding the potential harm associated with IIT $^{8}$, we believe attention should likewise be directed at factors that may contribute to hyperglycemia in the critically ill, such as nutritional support and/or use of corticosteroids. ${ }^{32,39}$ The initiation of nutritional support in critically ill patients is commonly believed to contribute to hyperglycemia. ${ }^{40}$ Regrettably, nutritional intake during studies evaluating IIT have generally been poorly defined. ${ }^{5}$ However, recent data have speculated that "under-feeding" patients to approximately $50 \%$ of estimated caloric targets may be associated with better clinical outcomes compared with feeding to standard caloric expectations. ${ }^{41}$ Whether this finding represents avoidance of relative "over-feeding" and/or iatrogenic hyperglycemia prompting insulin therapy remains unclear. However, this would suggest there may be important and poorly understood interactions between the stress of critical illness, nutritional support, reactive hyperglycemia, and exogenous insulin therapy that warrants careful investigation..$^{30,31}$ Moreover, these factors may be further complicated by augmented and/or impaired cerebral glucose metabolism in brain-injured patients.

We recognize there are limitations to our study that should be considered. First, this study was single-centred, retrospective and had limited power to detect clinically important measures of outcome. Second, during the study period, no specific protocol was implemented for BG control. We believe this was not an uncommon occurrence at the time our study was performed and that IIT during this period was not universally adopted..$^{42}$ Third, all BG sampling was performed by finger capillary sampling which may be prone to greater inaccuracy when compared to other measures such as arterial blood sampling. We were also not able to capture data on delivery of nutrition, the absolute quantity of insulin delivered, the duration of each episode of $\mathrm{BG}$ abnormality, or the use of concomitant corticosteroids and/or 
mannitol. We recognize that additional unmeasured variables may have accounted for some of the association between BG abnormalities and clinical outcomes we describe. Accordingly, our findings may be prone to bias and confounding and not broadly generalizable to all brain-injured and/or neurologic critically ill patients. Finally, we were not able to capture data on secondary outcomes (i.e. renal replacement therapy, critical illness neuromuscular complications, nosocomial infections) or data on the potential long-term sequelae (i.e. cognitive function, survival).

In summary, glycemic control in brain-injured ICU patients presents a unique therapeutic challenge. Overall, the occurrence of hypoglycemia, hyperglycemia and BG variability was relatively common in this cohort, however, their risk appeared to be significantly modified (higher) by the presence of pre-existing DM, and use of IIT. An increased frequency of episodes, in particular for BG variability or hyperglycemia, was associated with a higher risk of both hospital death and prolonged duration of stay. While the findings are unable to establish causality, they suggest further study to clarify the optimal method to achieve safe glycemic control and the ideal BG range to minimize risk in the brain-injured population is needed.

\section{ACKNOWLEDGEMENTS}

Dr. Bagshaw is supported by a Clinical Investigator Award from the Alberta Heritage Foundation for Medical Research.

\section{REFERENCES}

1. van den Berghe G, Wilmer A, Hermans G, Meersseman W, Wouters PJ, Milants I, et al. Intensive insulin therapy in the medical ICU. N Engl J Med. 2006;354(5):449-61.

2. Mitchell I, Knight E, Gissane J, Tamhane R, Kolli R, Leditschke IA, et al. A phase II randomised controlled trial of intensive insulin therapy in general intensive care patients. Crit Care Resusc. 2006;8(4):289-93.

3. Thomas G, Rojas MC, Epstein SK, Balk EM, Liangos O, Jaber BL. Insulin therapy and acute kidney injury in critically ill patients a systematic review. Nephrol Dial Transplant. 2007;22(10): 2849-55.

4. van den Berghe G, Wouters P, Weekers F, Verwaest C, Bruyninckx F, Schetz M, et al. Intensive insulin therapy in the critically ill patients. N Engl J Med. 2001;345(19):1359-67.

5. Finney SJ, Zekveld C, Elia A, Evans TW. Glucose control and mortality in critically ill patients. JAMA. 2003;290(15):2041-7.

6. Dellinger RP, Levy MM, Carlet JM, Bion J, Parker MM, Jaeschke $\mathrm{R}$, et al. Surviving Sepsis Campaign: international guidelines for management of severe sepsis and septic shock: 2008. Crit Care Med. 2008;36(1):296-327.

7. Krinsley JS. Association between hyperglycemia and increased hospital mortality in a heterogeneous population of critically ill patients. Mayo Clin Proc. 2003;78(12):1471-8.

8. NICE-SUGAR Investigators. Intensive versus conventional glucose control in critically ill patients. New Engl J Med. 2009;360(13): 1283-97.

9. Malmberg K, Ryden L, Efendic S, Herlitz J, Nicol P, Waldenstrom A, et al. Randomized trial of insulin-glucose infusion followed by subcutaneous insulin treatment in diabetic patients with acute myocardial infarction (DIGAMI study): effects on mortality at 1 year. J Am Coll Cardiol. 1995;26(1):57-65.

10. Gandhi GY, Nuttall GA, Abel MD, Mullany CJ, Schaff HV, O'Brien $\mathrm{PC}$, et al. Intensive intraoperative insulin therapy versus conventional glucose management during cardiac surgery: a randomized trial. Ann Intern Med. 2007;146(4):233-43.
11. Bilotta F, Caramia R, Cernak I, Paoloni FP, Doronzio A, Cuzzone $\mathrm{V}$, et al. Intensive insulin therapy after severe traumatic brain injury: a randomized clinical trial. Neurocrit Care. 2008;9(2): $159-66$.

12. Bilotta F, Spinelli A, Giovannini F, Doronzio A, Delfini R, Rosa G. The effect of intensive insulin therapy on infection rate, vasospasm, neurologic outcome, and mortality in neurointensive care unit after intracranial aneurysm clipping in patients with acute subarachnoid hemorrhage: a randomized prospective pilot trial. J Neurosurg Anesthesiol. 2007;19(3):156-60.

13. Oddo M, Schmidt JM, Carrera E, Badjatia N, Connolly ES, Presciutti M, et al. Impact of tight glycemic control on cerebral glucose metabolism after severe brain injury: a microdialysis study. Crit Care Med. 2008;36(12):3233-8.

14. Oddo M, Schmidt JM, Mayer SA, Chiolero RL. Glucose control after severe brain injury. Curr Opin Clin Nutr Metab Care. 2008; 11(2):134-9.

15. Schlenk F, Graetz D, Nagel A, Schmidt M, Sarrafzadeh AS. Insulinrelated decrease in cerebral glucose despite normoglycemia in aneurysmal subarachnoid hemorrhage. Crit Care. 2008;12 (1):R9.

16. Schlenk F, Sarrafzadeh AS. Is continuous insulin treatment safe in aneurysmal subarachnoid hemorrhage? Vasc Health Risk Manag. 2008;4(4):885-91.

17. Bagshaw SM, Egi M, George C, Bellomo R. Early blood glucose control and mortality in critically ill patients in Australia. Crit Care Med. 2009;37(2):463-70.

18. Krinsley JS. Glycemic variability: a strong independent predictor of mortality in critically ill patients. Crit Care Med. 2008;36(11): 3008-13.

19. Ali NA, O'Brien JM, Jr., Dungan K, Phillips G, Marsh CB, Lemeshow $\mathrm{S}$, et al. Glucose variability and mortality in patients with sepsis. Crit Care Med. 2008;36(8):2316-21.

20. Hirshberg E, Larsen G, Van Duker H. Alterations in glucose homeostasis in the pediatric intensive care unit: hyperglycemia and glucose variability are associated with increased mortality and morbidity. Pediatr Crit Care Med. 2008;9(4):361-6.

21. Dossett LA, Cao H, Mowery NT, Dortch MJ, Morris JM, Jr., May AK. Blood glucose variability is associated with mortality in the surgical intensive care unit. Am Surg. 2008;74(8):679-85; discussion 85.

22. Krinsley JS, Preiser JC. Moving beyond tight glucose control to safe effective glucose control. Crit Care. 2008;12(3):149.

23. Arabi YM, Dabbagh OC, Tamim HM, Al-Shimemeri AA, Memish $\mathrm{ZA}$, Haddad SH, et al. Intensive versus conventional insulin therapy: a randomized controlled trial in medical and surgical critically ill patients. Crit Care Med. 2008;36(12):3190-7.

24. Brunkhorst FM, Engel C, Bloos F, Meier-Hellmann A, Ragaller M, Weiler $\mathrm{N}$, et al. Intensive insulin therapy and pentastarch resuscitation in severe sepsis. N Engl J Med. 2008;358(2): 125-39.

25. Wiener RS, Wiener DC, Larson RJ. Benefits and risks of tight glucose control in critically ill adults: a meta-analysis. JAMA. 2008;300(8):933-44.

26. Krinsley JS, Grover A. Severe hypoglycemia in critically ill patients: risk factors and outcomes. Crit Care Med. 2007;35 (10):2262-7.

27. Preiser JC, Devos P. Clinical experience with tight glucose control by intensive insulin therapy. Crit Care Med. 2007;35 Suppl 9: S503-7.

28. Preiser JC, Brunkhorst F. Tight glucose control and hypoglycemia. Crit Care Med. 2008;36(4):1391; author reply -2.

29. Vriesendorp TM, DeVries JH, van Santen S, Moeniralam HS, de Jonge E, Roos YB, et al. Evaluation of short-term consequences of hypoglycemia in an intensive care unit. Crit Care Med. 2006; 34(11):2714-8.

30. Andersen SK, Gjedsted J, Christiansen C, Tonnesen E. The roles of insulin and hyperglycemia in sepsis pathogenesis. J Leukoc Biol. 2004;75(3):413-21.

31. Marik PE, Raghavan M. Stress-hyperglycemia, insulin and immunomodulation in sepsis. Intensive Care Med. 2004;30(5): 748-56. 
32. Roberts I, Yates D, Sandercock P, Farrell B, Wasserberg J, Lomas $\mathrm{G}$, et al. Effect of intravenous corticosteroids on death within 14 days in 10008 adults with clinically significant head injury (MRC CRASH trial): randomised placebo-controlled trial. Lancet. 2004;364(9442):1321-8.

33. Yamamura H, Hiraide A, Matsuoka T, Takaoka M, Shimazu T, Sugimoto H. Does growth hormone augment brain edema caused by brain injury? A study with a freeze brain injury model in the rat. J Trauma. 1999;46(2):292-6.

34. Godoy DA, Pinero GR, Svampa S, Papa F, Di Napoli M. Hyperglycemia and short-term outcome in patients with spontaneous intracerebral hemorrhage. Neurocrit Care. 2008; 9(2):217-29.

35. Waeschle RM, Moerer O, Hilgers R, Herrmann P, Neumann P, Quintel M. The impact of the severity of sepsis on the risk of hypoglycaemia and glycaemic variability. Crit Care. 2008;12 (5):R129.

36. Wittenberg MD, Gattas DJ, Ryan A, Totaro R. Introduction of intensive glycaemic control into a neurosurgical intensive care unit: a retrospective cohort study. Crit Care Resusc. 2008; 10(3):203-8.
37. Lacherade JC, Jabre P, Bastuji-Garin S, Grimaldi D, Fangio P, Theron V, et al. Failure to achieve glycemic control despite intensive insulin therapy in a medical ICU: incidence and influence on ICU mortality. Intensive Care Med. 2007;33(5): 814-21.

38. Shaw GM, Chase JG, Wong J, Lin J, Lotz T, Le Compte AJ, et al. Rethinking glycaemic control in critical illness--from concept to clinical practice change. Crit Care Resusc. 2006;8(2):90-9.

39. Jeejeebhoy KN. Permissive underfeeding of the critically ill patient. Nutr Clin Pract. 2004;19(5):477-80.

40. Powell-Tuck J. Nutritional interventions in critical illness. Proc Nutr Soc. 2007;66(1):16-24.

41. Krishnan JA, Parce PB, Martinez A, Diette GB, Brower RG. Caloric intake in medical ICU patients: consistency of care with guidelines and relationship to clinical outcomes. Chest. 2003; 124(1):297-305.

42. Mitchell I, Finfer S, Bellomo R, Higlett T. Management of blood glucose in the critically ill in Australia and New Zealand: a practice survey and inception cohort study. Intensive Care Med. 2006;32(6):867-74. 